\title{
Decision analysis based on optimisation
}

\author{
Anne-Sophie Crépin ${ }^{1}$ and Stephen Polasky ${ }^{2}$ \\ ${ }^{1}$ BEIJER INSTITUTE OF ECOLOGICAL ECONOMICS, THE ROYAL SWEDISH ACADEMY OF SCIENCES, \\ STOCKHOLM, SWEDEN \\ ${ }^{2}$ UNIVERSITY OF MINNESOTA, MINNEAPOLIS, MINNESOTA, USA
}

\section{Key methods discussed in this chapter}

Mathematical programming, optimal control theory, game theory, decision theory, costbenefit analysis, multi-criteria decision analysis

\section{Connections to other chapters}

Methods for data generation and systems scoping (Chapters 5-8), futures analysis (Chapter 10), scenario development (Chapter 11), dynamical systems modelling (Chapter 26), state-and-transition modelling (Chapter 27), agent-based modelling (Chapter 28) and other methods for analysing systems (Chapters 30-32) can be used to inform decision processes. Controlled behavioural experiments (Chapter 21) can help to evaluate potential impacts of decisions. The methods in this chapter can help to model people's behaviour in futures analysis, scenario development, dynamical systems modelling and agent-based modelling.

\section{Introduction}

Decision analysis is a systematic approach to evaluating information about alternative choices, when multiple options are possible, with many possible outcomes and different trade-offs. In social-ecological systems (SES), multiple types of decisions (policy, management, private, other) - all with different objectives - influence the social, economic and ecological dimensions, making it hard to compare across alternatives. Decision analysis can analyse these situations and their impacts on individual actors, society and the rest of the system.

The objective of a decision can, for example, be related to maximising measures of human well-being ('utility') or reaching a particular target, such as remaining below a maximum level of pollution, reducing inequality or conserving biodiversity. These decisions also involve multiple constraints, e.g. the desire to remain within a given budget, or the physical restrictions posed by particular ecosystem dynamics. Selecting from several possible decisions requires specific criteria for assessment. Here we focus on optimisation as a criterion.

The problem of optimisation has been of interest for centuries in mathematics. Optimisation methods are used in a wide array of disciplines including decision science, economics, engineering, 


\begin{tabular}{|c|c|}
\hline DISCIPLINARY BACKGROUND & KNOWLEDGE TYPE \\
\hline $\begin{array}{l}\text { The methods in this chapter are derived } \\
\text { from or have most commonly been used in: } \\
\text { Mathematics, Engineering, Economics, } \\
\text { Physics, Political Sciences, Sociology, } \\
\text { Biology }\end{array}$ & $\begin{array}{l}\text { The methods in this chapter are primarily } \\
\text { used to generate the following types of } \\
\text { knowledge: } \\
\text { - Descriptive } \\
\text { - Exploratory } \\
\text { - Explanatory } \\
\text { - Prescriptive }\end{array}$ \\
\hline RESEARCH APPROACH & PURPOSE OF METHOD \\
\hline $\begin{array}{l}\text { The methods in this chapter originate } \\
\text { from or most commonly adopt the } \\
\text { following research approaches: } \\
\text { - Analytical/objective }\end{array}$ & $\begin{array}{l}\text { The most common purposes of using the } \\
\text { methods in this chapter are: } \\
\text { - System understanding } \\
\text { - Policy/decision support }\end{array}$ \\
\hline TEMPORAL DIMENSION & SYSTEMIC FEATURES AND PROCESSES \\
\hline $\begin{array}{l}\text { The methods in this chapter are most } \\
\text { commonly applied to the following } \\
\text { temporal dimensions: } \\
\text { - Present (typically within the last } \\
5-10 \text { years) } \\
\text { - Recent past (post-1700s) } \\
\text { - Pre-industrial revolution (pre-1700s) } \\
\text { - Future }\end{array}$ & $\begin{array}{l}\text { While most methods can do many } \\
\text { things, the methods in this chapter are } \\
\text { particularly good (i.e. go-to methods) for } \\
\text { addressing the following: } \\
\text { - SES components and linkages } \\
\text { - Social-ecological dependence } \\
\text { and impact } \\
\text { - Evaluating policy options }\end{array}$ \\
\hline SPATIAL DIMENSION & \\
\hline $\begin{array}{l}\text { The methods in this chapter are primarily } \\
\text { either or both: } \\
\text { - Non-spatial } \\
\text { - Explicitly spatial }\end{array}$ & \\
\hline $\begin{array}{l}\text { The methods in this chapter are most } \\
\text { commonly applied at the following } \\
\text { spatial scales: } \\
\text { - Local } \\
\text { - Regional (provincial/state } \\
\text { to continental) } \\
\text { - Global } \\
\text { - Multiple places/sites around the world }\end{array}$ & \\
\hline
\end{tabular}


mathematics, political science, psychology and sociology. These methods build on early attempts (sometimes dating back to ancient Greece) to solve problems related to risk management, resource allocation and strategic interactions, which occur in all SES. Strategic interactions are likely to influence people's own objectives and how they expect others to react. Methods to analyse strategic interactions assess people's expected actions and how their interactions are likely to influence the SES outcome. Here we focus on game theory, which studies the interactions of multiple optimising agents. This method was already documented in the early 18th century.

Decision analysis methods in SES typically use models to predict how various choices made by actors affect the evolution of the SES and how the system in turn affects the individual or collective objective. Among those methods, optimisation methods then search through possible choices to find the one that generates the highest score for the objective. Game theory searches instead for the equilibrium likely to occur from people's interactions. Decision analysis in the context of SES must incorporate social and ecological components with feedbacks among components that accurately capture the system's dynamic behaviour (Polasky et al. 2011). At least four aspects of these dynamics substantially influence the choice of the method that would be appropriate for decision analysis:

1. Who is making the decision? A centralised decision process implies that someone has exclusive power to make a decision or that all agents agree to abide by a group decision. The decision-maker could, for example, be a national government, an individual allocating their own resources or a community managing a common resource. In contrast, a decentralised decision process involves several people, all with different objectives and criteria for assessing their objective. While optimisation methods are most useful for studying centralised decision processes, game theory analyses the different actors' decision options and the outcomes of decentralised processes.

2. How much information is available? The amount of information available is important, in particular whether there is full certainty (complete knowledge), risk (the outcome is unknown, but all possible outcomes and their probabilities are known) or uncertainty (some outcomes and/or their probabilities are unknown). Risk situations require stochastic optimisation methods, which are particular methods that maximise some expected value of the objective (e.g. expected utility). In contrast, uncertainty requires the use of methods such as futures analysis (Chapter 10), scenario development (Chapter 11) or resilience assessments (Chapter 14). Information may not be evenly distributed among agents. Economic theories of decisions with imperfect information for problems of moral hazard (e.g. an insured person taking more risk than an uninsured one), principal agents (e.g. a person taking action on behalf of another) or asymmetric information (e.g. a seller of a product knowing more about its quality than a buyer) can use game theory to inform policy design and studies of power relationships and decisions in the social part of SES.

3. Is there a temporal dimension? Some decision analyses focus on one-shot decisions and use so-called static optimisation methods, whereas others incorporate processes that evolve with time and use dynamic optimisation methods. Mathematical programming is a static optimisation method, while optimal control methods are dynamic. Time can be modelled as a continuous or discrete process, with each process requiring different optimisation technologies. Modelling strategic interactions also entails using different tools depending on the timing of the different individuals' decisions. People can act simultaneously (static games), after one another (sequential games), once (one-shot games), repeatedly (repeated games), or take into account dynamic processes (dynamic games) and evolution (evolutionary games). 
4. Are there any spatial patterns? Most decision analysis methods were developed without explicit spatial considerations. However, optimisation and game theory can be adapted to account for spatial heterogeneity and spatial interactions when decisions made in one place affect the net benefits of making decisions somewhere else (Costello and Polasky 2008; Polasky et al. 2008, 2014; Smith, Sanchirico, and Wilen 2009; Brock and Xepapadeas 2010).

Optimisation and game theory rely on a number of important assumptions. Varying some of these assumptions contributes to theory development in these fields. The study of SES, in particular slow and delayed time processes, for example, has led to borrowing methods from mathematics, such as perturbation theory (Crépin 2007), or new ways of modelling risk with delays (Crépin and Nævdal 2020). The field of behavioural economics has grown in response to the observation that, in many situations, people do not behave in a way consistent with rational choice, i.e. choices that are in their perceived best interest. Researchers at the boundary between psychology and economics have introduced new explanations such as bounded rationality and prospect theory to explain these deviations (Shogren and Taylor 2008).

Another important assumption in optimisation methods is that the systems being studied are well behaved, which leads to a single optimum equilibrium. Research on economies of scales identified the existence of two possible optimal equilibria and an indifference point where either equilibrium could be an optimal target for management (Skiba 1978) depending on initial conditions. Complexity economics (Arthur 1999) emerged partly in response to observations that many of the systems studied were complex adaptive systems with possibly multiple and complex attractors, rather than a unique optimal equilibrium.

\section{SES problems and questions}

Decision analysis is essential to modelling social dynamics in SES models, exploring and testing SES behaviour, and comparing the outcomes of different policies under various conditions. Optimisation methods can help to answer questions such as the following: "where should various interventions occur?' (Polasky et al. 2008); 'what would be the optimal release of nutrients in a lake given that users value both water quality and agricultural production on the shore?' (Mäler, Xepapadeas, and De Zeeuw 2003); 'how much fish should we harvest in a coral reef?' (Crépin 2007). Game theory can address questions such as the following: 'what would be the outcome in the lake if the users did not cooperate?' (Mäler, Xepapadeas and De Zeeuw 2003); 'if farmers did not cooperate, how many animals would each farmer allow to graze on a common grassland?' (Crépin and Lindahl 2009). Cost-benefit analysis and multi-criteria decision analysis can help to answer questions such as 'what investment should we make?' and 'which alternative should we choose among those possible?'.

Case study 29.1 illustrates these different options to inform decisions in a community managing a lake. Optimisation and game theory can also enrich other methods that are often used in the study of SES, in particular bio-economic modelling and agent-based models (Chapter 28), where they contribute to testing the impacts of a wide array of different behaviours and assumptions on the outcome of the model.

\section{Brief description of key methods}

Decision analysis includes many methods that can be used for various purposes. Those selected in Table 29.1 represent the variety of methods using optimisation, which take into 
Table 29.1 Summary of key methods used in decision analysis based on optimisation

\begin{tabular}{|c|c|c|}
\hline Method & Description & References \\
\hline $\begin{array}{l}\text { Mathematical } \\
\text { programming }\end{array}$ & $\begin{array}{l}\text { Mathematical methods are used to solve } \\
\text { optimisation problems when decision is } \\
\text { centralised, full information is available } \\
\text { and time does not matter. Some of these } \\
\text { methods (e.g. Lagrange and Kuhn- } \\
\text { Tucker methods) address situations when } \\
\text { constraints (e.g. a budget that must be } \\
\text { fully spent or a pollution level that cannot } \\
\text { be transgressed) limit the range of possible } \\
\text { decisions. }\end{array}$ & $\begin{array}{l}\text { Key introductory text } \\
\text { Intriligator } 2002 \\
\text { Applications to SES } \\
\text { Robinson, Williams, and Albers } \\
2002 ; \\
\text { Watson et al. } 2011\end{array}$ \\
\hline Game theory & $\begin{array}{l}\text { Game theory involves mathematical } \\
\text { methods to study the outcomes of strategic } \\
\text { interactions, usually between rational } \\
\text { decision-makers. A fully defined game } \\
\text { specifies the players of the game (e.g. } \\
\text { all users of a lake), the information and } \\
\text { actions available to each player at each } \\
\text { decision point (e.g. to fish or not), the order } \\
\text { in which actions can be taken (who gets } \\
\text { to fish when), and the pay-offs of each } \\
\text { outcome. In the simplest solution concept } \\
\text { (called the Nash equilibrium), each actor } \\
\text { maximises their expected utility given the } \\
\text { equilibrium behaviour of other actors. More } \\
\text { complex games incorporate aspects like } \\
\text { time (repeated, differential and evolutionary } \\
\text { games) and asymmetric information } \\
\text { between players. }\end{array}$ & $\begin{array}{l}\text { Key introductory text } \\
\text { Myerson } 2013 \\
\text { Applications to SES } \\
\text { Mäler, Xepapadeas, and De } \\
\text { Zeeuw 2003; } \\
\text { Crépin and Lindahl 2009; } \\
\text { Diekert 2012; } \\
\text { Tavoni, Schlüter, and Levin } \\
2012\end{array}$ \\
\hline $\begin{array}{l}\text { Optimal control } \\
\text { theory }\end{array}$ & $\begin{array}{l}\text { Optimal control theory is a set of } \\
\text { mathematical methods to solve optimisation } \\
\text { problems when decision is centralised, full } \\
\text { information is available and some variables } \\
\text { change over time. The methods aim to } \\
\text { identify the values of a variable (control) } \\
\text { that can be manipulated (e.g. the size of a } \\
\text { harvest) to optimise a particular objective } \\
\text { of a system (e.g. the sum of profits from a } \\
\text { fishery over time). The dynamics of some } \\
\text { system variable (e.g. how the fish stock } \\
\text { changes over time) limit the range of possible } \\
\text { decisions along with other constraints } \\
\text { (e.g. how much fish should be left at the } \\
\text { end of the period). These methods include } \\
\text { calculus of variation, dynamic programming } \\
\text { (also useful for computer programming) and } \\
\text { Pontryagin's maximum principle. }\end{array}$ & $\begin{array}{l}\text { Key introductory text } \\
\text { Kamien and Schwartz } 2012 \\
\text { Applications to SES } \\
\text { Crépin 2007; } \\
\text { Diekert et al. 2010; } \\
\text { Quaas et al. 2013; } \\
\text { Ashander et al. } 2019\end{array}$ \\
\hline
\end{tabular}




\begin{tabular}{|c|c|c|}
\hline Method & Description & References \\
\hline Decision theory & $\begin{array}{l}\text { Decision theory is a collection of decision } \\
\text { methods that incorporate risk and } \\
\text { uncertainty. With risk, the objective can } \\
\text { be expressed as an expected value, and } \\
\text { stochastic optimisation methods can } \\
\text { be applied. With uncertainty, different } \\
\text { decision rules are available depending on } \\
\text { whether the decision-maker puts more } \\
\text { weight on precaution, confidence in } \\
\text { information about the relative likelihood } \\
\text { of outcomes, robustness of choice, or } \\
\text { flexibility in the timing of the decision. } \\
\text { Decision rules emerging from this process } \\
\text { could, for example, aim to minimise regrets } \\
\text { associated with a decision, minimise } \\
\text { potential losses or maximise best possible } \\
\text { outcomes. }\end{array}$ & $\begin{array}{l}\text { Key introductory text } \\
\text { Morgan and Henrion } 1990 \\
\text { Applications to SES } \\
\text { Polasky, De Zeeuw, and } \\
\text { Wagener 2011; } \\
\text { Cox } 2012\end{array}$ \\
\hline $\begin{array}{l}\text { Cost-benefit } \\
\text { analysis }\end{array}$ & $\begin{array}{l}\text { Cost-benefit analysis (CBA) is a systematic } \\
\text { approach to determine whether an } \\
\text { investment is sound by comparing the } \\
\text { net present value of different investments. } \\
\text { CBA identifies the flow of all the costs } \\
\text { and benefits over time associated with a } \\
\text { particular project. A CBA should contain } \\
\text { a comparison between one and more } \\
\text { particular development projects and the } \\
\text { status quo. }\end{array}$ & $\begin{array}{l}\text { Key introductory text } \\
\text { Boadway } 2016 \\
\text { Applications to SES } \\
\text { Bateman et al. 2003; } \\
\text { Pearce, Atkinson, and Mourato } \\
\text { 2006; } \\
\text { Wegner and Pascual } 2011\end{array}$ \\
\hline $\begin{array}{l}\text { Multi-criteria } \\
\text { decision analysis }\end{array}$ & $\begin{array}{l}\text { Multi-criteria decision analysis (MCDA) } \\
\text { uses formal approaches that take explicit } \\
\text { account of multiple criteria in exploring } \\
\text { decisions. MCDA applies in particular } \\
\text { when the criteria to take into account are } \\
\text { sufficiently important for the outcome } \\
\text { of the decision and some of them may } \\
\text { conflict with one another. There is typically } \\
\text { not a unique optimal solution to this } \\
\text { problem; instead, the goal may be to find } \\
\text { the preferred alternative among several or } \\
\text { to find all solutions that would not sacrifice } \\
\text { at least one dimension. }\end{array}$ & $\begin{array}{l}\text { Key introductory text } \\
\text { Mendoza and Martins } 2006 \\
\text { Applications to SES } \\
\text { Karjalainen et al. } 2013\end{array}$ \\
\hline
\end{tabular}

account three of the four important aspects mentioned in the introduction (i.e. who is making the decision, the amount of information available, the temporal dimension). Although these methods were not specifically developed with spatial variations, it is possible to incorporate such heterogeneity - but then often at the expense of more complex solutions.

Mathematical programming solves the simplest optimisation problems if decision-making is centralised, there is full certainty and time does not influence the outcome. Many daily 
decisions in SES emerge from the strategic interactions of multiple stakeholders who do not necessarily cooperate, such as a small number of firms competing with one another or users of a common-pool fishery. Game theory aims to study these types of strategic interactions when the decision is decentralised. Optimal control theory covers optimisation methods over time, with centralised decisions and full certainty, whereas decision theory focuses on optimisation methods when some information is missing.

In contrast to these theoretical methods, cost-benefit analysis and multi-criteria decision analysis are of a more practical nature. They apply to centralised decisions and are useful for choosing among multiple project alternatives when more detailed information is available (Polasky and Binder 2012). Cost-benefit analysis measures all have a monetary impact and compare alternatives in terms of net benefits (benefits minus costs) to find optimal policy or management choices. Multi-criteria decision analysis methods were developed to structure, analyse and solve decision problems involving multiple criteria measured in different metrics.

\section{Limitations}

Despite their powerful and broad applicability, decision analysis methods are based on simplified models that limit the ability to fully represent complex SES dynamics. Optimisation and game theory methods both focus on equilibria, but system dynamics outside of any equilibrium are also important in the study of SES. Decision analysis methods that explicitly incorporate time variations can be used to analyse dynamics outside of equilibrium, but this usually requires computer simulations even for relatively simple problems. There is currently no example of an optimisation or game theory model that simultaneously incorporates all typical characteristics of SES as a complex adaptive system (Levin et al. 2013). Such models would be extremely hard if not impossible to fully analyse. The information obtained may not be meaningful because the results could be very sensitive to initial conditions and model assumptions.

Different assumptions about preferences, how they trade off against one another and in time, and different decision criteria can result in widely different recommendations about possible actions. Individual decision-making involves subjective tastes and preferences. Decision processes involving several people require weighting the preferences of different individuals against one another, and trading off values between today and the future. Uncertainty and the choice of appropriate decision criteria generate yet another layer of subjectivity. Any outcome from a decision analysis therefore needs to be carefully considered and understood in terms of the assumptions it relies on. Sensitivity analyses are an important component of any analysis to explore how the optimal outcome changes given different assumptions.

Cost-benefit analysis and multi-criteria decision analysis tend to neglect aspects of decisions that are difficult to quantify and value, compared to easily quantifiable variables. Data of sufficient resolution for both natural and social variables are often not available and information about causal relationships related to behavioural, social, economic, ecological and technical aspects is generally lacking. The difference in timing when the costs and benefits are estimated can generate decision biases because the cost occurring today is easier to estimate than the uncertain future costs and benefits.

Game theory is particularly challenging to apply when studying decisions in larger groups. With more than two players, it becomes difficult to represent all possibilities. To address this issue, one could study the behaviour of an average player or simulate many potential outcomes to identify the distribution of these outcomes given a set of potential responses and initial conditions. Agent-based models (Chapter 28) are probably better suited to representing the outcomes of strategic interactions between many heterogeneous agents. 


\section{Resource implications}

Using decision analysis methods based on optimisation requires mathematical training. Basic mathematics is enough to solve the simplest mathematical programs, cost-benefit analyses and games. However, many of the methods studied hinge on advanced mathematics to model and analyse multiple kinds of dynamic, stochastic and spatial processes. Cost-benefit analysis and multi-criteria decision analysis also require using methods (such as valuation methods) to quantify expected changes and find ways to compare these changes to one another.

Problems with SES dynamics are so complex that they typically do not have any analytical solutions. Instead, numerical analysis can identify solution properties through computer simulations using, for example, Monte Carlo methods, which replicate the studied system using a large number of different parameter values. Model investigations over the whole range of possible parameter values require extensive computing power to perform numerous iterations. Careful model calibration to real data, with good quality data, can limit the necessary number of iterations.

While it is straightforward to program discrete time models, continuous time models are more problematic because computers can only handle discrete time steps. The RungeKutta methods were developed for the purpose of approximating the solutions to ordinary differential equations. These methods are usually available as a standard package of the most commonly used software for mathematical programming and numerical analysis.

\section{New directions}

The methods presented in this chapter contribute to SES analysis but were not designed for this purpose. Further progress should broaden these methods to account for the complex adaptive systems properties of SES (Levin et al. 2013). More interaction with the field of complexity economics (Arthur 1999, 2006) could be fruitful, including the study of dynamics outside of equilibrium and more heterogeneous agents.

Substantial effort has been made to incorporate elements of complexity in standard optimisation and game theory tools. With the appropriate assumptions, these methods can help to analyse regime shifts (Grass et al. 2008), spatial heterogeneity (Brock and Xepapadeas 2010), diversity (Crépin, Norberg, and Mäler 2011), and fast and slow variables (Crépin 2007). Resource economics has investigated management with multiple attractors for a variety of ecosystems (e.g. forests: Crépin 2003; lakes: Mäler, Xepapadeas, and De Zeeuw 2003; coral reefs and fisheries: Crépin 2007). Recent developments have also focused on the role of spatial heterogeneity and spatial interactions (Polasky et al. 2008; Smith, Sanchirico, and Wilen 2009; Brock and Xepapadeas 2010, 2019; Epanchin-Niell and Wilen 2012), diversity (Van der Heide, Van den Bergh, and Van Ierland 2005), learning (Peterson, Carpenter, and Brock 2003), uncertainty about critical thresholds (Polasky, De Zeeuw, and Wagener 2011) and other aspects relevant to SES.

Agent-based models, resilience assessments and scenario planning often only include poor representation of the economic incentives that influence the behaviour of different agents or groups of agents (Crépin 2019). These approaches should start using the methods presented in this chapter in a more systematic way. Some progress in this direction includes a framework for integrated ecosystem-based management that aims to merge ecosystem-based management, economic decision approaches and an SES perspective, accounting for aspects that influence system resilience (Crépin et al. 2017).

The impacts of uneven distribution of information among people have been widely studied using the methods presented in this chapter. However, these studies usually neglect further complexity. It could be fruitful to revisit key studies of complex strategic human 


\section{Case study 29.1: Decision analysis and the management of North Temperate Lakes in Wisconsin, USA}

The North Temperate Lakes (NTL) Long-Term Ecological Research (LTER) site studies the ecology of seven lakes in Wisconsin, USA. It focuses on how biophysical setting, climate and changing land use and land cover interact to shape lake characteristics and dynamics over time. Figure 29.1, for example, shows Lake Mendota and Lake Monona. Both lakes have regular algal blooms, due primarily to nutrient run-off from dairy manure and eroding agricultural fields. The aim of the project, which started in 1981, was to study long-term change and ecosystem regime shifts and assess their potential causes.

Using long-term monitoring and large-scale experimentation, researchers could identify multiple drivers of ecosystem change such as extreme events and land-use

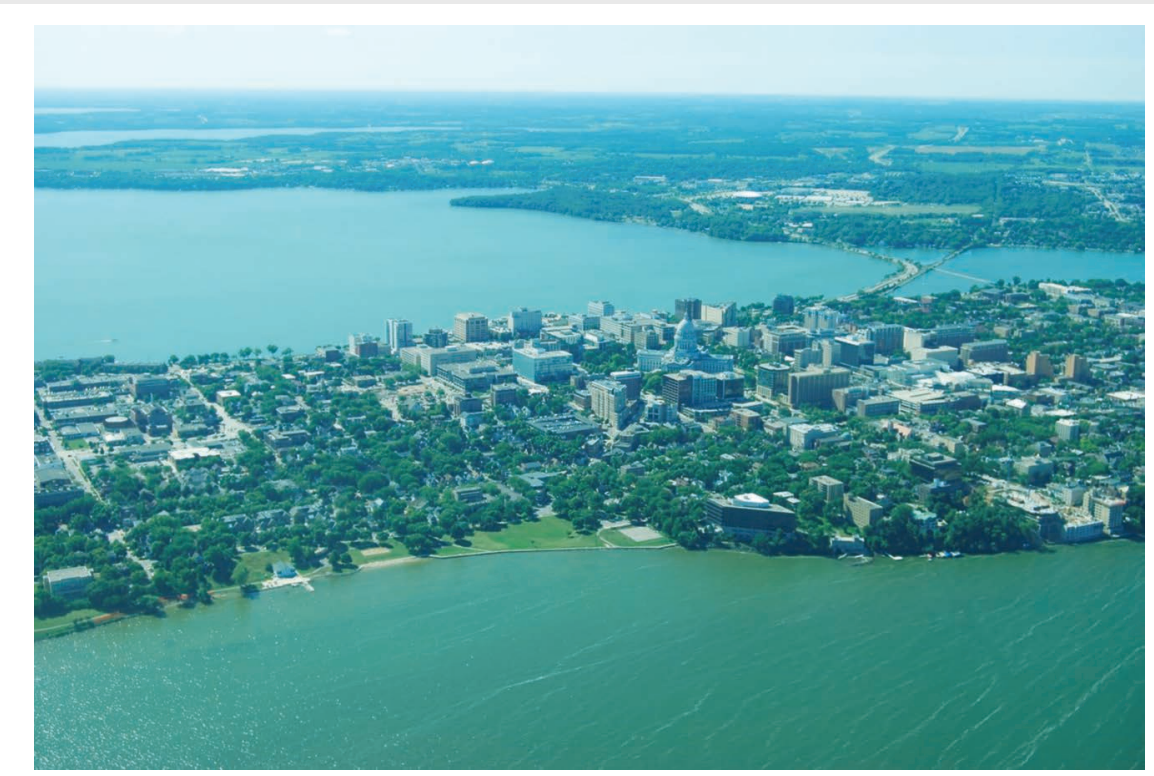

Figure 29.1 The isthmus of Madison, Wisconsin, with Lake Mendota in the foreground and Lake Monona in the background (@ Eric Booth 2014)

behaviour by placing them in an SES context or to introduce agents with various degrees of information and complex strategic behaviour into agent-based models.

Another blind spot concerns strategic interactions when regime shifts occur in a spatial context. Earlier results investigating strategic considerations and behavioural responses with regime shifts show a very rich set of strategic responses compared to when there are no regime shifts (Schill, Lindahl, and Crépin 2015). The same holds true for investigations relating to the optimisation of resource use with regime shifts and spatial heterogeneity (Brock and Xepapadeas 2019). Integrating all these dimensions is likely to provide novel insights. 
changes. These could lead to altered nutrient inflows, which could, beyond a certain threshold, trigger a regime shift. This knowledge led to simplified mathematical models of lakes. Other scientists (e.g. Mäler, Xepapadeas, and De Zeeuw 2003) could then use these simplified models as constraints in models of decision analysis. Optimal control models could answer the question 'What is the optimal amount of nutrient release from agriculture to a lake?' and differential game models would answer the questions 'What will be the release of nutrients to the lake if land users do not cooperate?' and 'Can we design a tax on nutrients that will achieve the optimal amount of nutrient release even if land users do not cooperate?' (Mäler, Xepapadeas, and De Zeeuw 2003; Kossioris et al. 2011).

These studies showed, for example, that for some initial conditions it might be optimal to release so many nutrients into the lake that its water would become turbid, while for other initial conditions the lake water should remain clear of nutrients. Indeed, the outcome would depend on how the value of having a clear lake is traded off against the value of being able to release nutrients (e.g. to grow crops on the shore). If the community did not manage to cooperate, they would reach a suboptimal outcome, which could trigger a regime shift to a turbid lake although it would have been optimal to keep the lake clear. The studies also showed that a tax scheme designed to reach an optimal nutrient release when the community does not cooperate would be extremely complicated and probably difficult to implement.

An advantage of using decision analysis based on optimisation in a dynamic context is that one can characterise not only the long-term equilibrium outcomes but also the complete path leading to these outcomes. Doing so revealed that while the long-term optimal equilibrium could in theory be achieved using a constant tax, the path leading to this outcome was suboptimal and contained discontinuities. This triggered discussion about whether such a tax would be successful at all.

While decision theory methods applied to simpler decision problems are able to reveal general rules and patterns, it is much more difficult to identify these patterns when decision analysis is applied to a more complex problem like the management of lakes that can exhibit regime shifts. The models used in this context were tractable only because they were substantially simplified (one differential equation expressing the nutrient dynamics). If the system is more complex, the solution to these types of problems must rely on advanced computational techniques. However, for lake management, the general results seem to be robust in more complex models that also incorporate a slow mud dynamics equation in addition to the nutrient dynamics (Grass, Xepapadeas, and De Zeeuw 2017).

\section{Key readings}

Grass, D., J.P. Caulkins, G. Feichtinger, G. Tragler, and D.A. Behrens. 2008. Optimal Control of Nonlinear Processes. Berlin: Springer.

Schmedders, K., and K.L. Judd. 2014. Handbook of Computational Economics, Volume 3. Amsterdam: Elsevier.

Seierstad, A., and K. Sydsæter. 1987. Optimal Control Theory with Economic Applications. Amsterdam: North Holland. 


\section{Acknowledgements}

We thank the Kjell and Märta Beijer Foundation for financial support.

\section{References}

Arthur, W.B. 1999. 'Complexity and the Economy.' Science 284(5411): 107-109.

Arthur, W.B. 2006. 'Out-of-equilibrium Economics and Agent-based Modeling.' Handbook of Computational Economics 2: 1551-1564.

Ashander, J., L.C. Thompson, J.N. Sanchirico, and M.L. Baskett. 2019. 'Optimal Investment to Enable Evolutionary Rescue.' Theoretical Ecology 12: 165-177.

Bateman, I.J., A.A. Lovett, J.S. Brainard, and D.W. Pearce. 2003. Applied Environmental Economics: A GIS Approach to Cost-benefit Analysis. Cambridge: Cambridge University Press.

Boadway, R. 2016. 'Cost-benefit Analysis.' In The Oxford Handbook of Well-being and Public Policy, edited by M.D. Adler and M. Fleurbaey, 47-81. New York: Oxford University Press.

Booth, E. 2014. Water Sustainability and Climate Project. https://wsc.limnology.wisc.edu.

Brock, W., and A. Xepapadeas. 2010. 'Pattern Formation, Spatial Externalities and Regulation in Coupled Economic-Ecological Systems.' Journal of Environmental Economics and Management 59(2): 149-164.

Brock, W., and A. Xepapadeas. 2019. 'Regional Climate Change Policy under Positive Feedbacks and Strategic Interactions.' Environmental and Resource Economics 72(1): 51-75.

Costello, C., and S. Polasky. 2008. 'Optimal Harvesting of Stochastic Spatial Resources.' Journal of Environmental Economics and Management 56(1): 1-18.

Cox, L.A. Jr. 2012. 'Community Resilience and Decision Theory Challenges for Catastrophic Events.' Risk Analysis: An International Journal 32(11): 1919-1934.

Crépin, A-S. 2003. 'Multiple Species Boreal Forests - What Faustmann Missed.' Environmental and Resource Economics 26(4): 625-646.

Crépin, A-S. 2007. 'Using Fast and Slow Processes to Manage Resources with Thresholds.' Environmental and Resource Economics 36(2): 191-213.

Crépin, A-S. 2019. 'Complexity, Resilience and Economics.' In Global Challenges, Governance, and Complexity: Applications and Frontiers, edited by V. Galaz, 166-187. Cheltenham: Edward Elgar.

Crépin, A-S., Å. Gren, G. Engström, and D. Ospina. 2017. 'Operationalising a Social-Ecological System Perspective on the Arctic Ocean.' Ambio 46(Supplement 3): S475-S485.

Crépin, A-S., and T. Lindahl. 2009. 'Grazing Games: Sharing Common Property Resources with Complex Dynamics.' Environmental and Resource Economics 44: 29-46.

Crépin, A-S., and E. Nævdal. 2020. 'Inertia in Risk: Improving Economic Models of Catastrophes.' Scandinavian Journal of Economics 122(4): 1259-1285. doi:10.1111/sjoe.12381.

Crépin, A-S., J. Norberg, and K.G. Mäler. 2011. 'Coupled Economic-ecological Systems with Slow and Fast Dynamics - Modelling and Analysis Method.' Ecological Economics 70(8): 1448-1458.

Diekert, F.K. 2012. 'The Tragedy of the Commons from a Game-theoretic Perspective.' Sustainability 4(8): 1776-1786.

Diekert, F.K., D.Ø. Hjermann, E. Nævdal, and N.C. Stenseth. 2010. 'Spare the Young Fish: Optimal Harvesting Policies for North-East Arctic Cod.' Environmental and Resource Economics 47(4): $455-475$.

Epanchin-Niell, R.S., and J.E. Wilen. 2012. 'Optimal Spatial Control of Biological Invasions.' Journal of Environmental Economics and Management 63(2): 260-270.

Grass, D., J.P. Caulkins, G. Feichtinger, G. Tragler, and D.A. Behrens. 2008. Optimal Control of Nonlinear Processes. Berlin: Springer.

Grass, D., A. Xepapadeas, and A. de Zeeuw. 2017. 'Optimal Management of Ecosystem Services with Pollution Traps: The Lake Model Revisited.' Journal of the Association of Environmental and Resource Economists 4(4): 1121-1154.

Intriligator, M.D. 2002. Mathematical Optimization and Economic Theory. Philadelphia: Society for Industrial and Applied Mathematics.

Kamien, M.I., and N.L. Schwartz. 2012. Dynamic Optimization: The Calculus of Variations and Optimal Control in Economics and Management. North Chelmsford: Courier Corporation.

Karjalainen, T.P., P.M. Rossi, P. Ala-Aho, R. Eskelinen, K. Reinikainen, B. Kløve, M. PulidoVelasquez, and H. Yang. 2013. 'A Decision Analysis Framework for Stakeholder Involvement and Learning in Groundwater Management.' Hydrology and Earth System Sciences 17: 1-13. 
Kossioris, G., M. Plexousakis, A. Xepapadeas, and A. de Zeeuw. 2011. 'On the Optimal Taxation of Common-pool Resources.' Journal of Economic Dynamics and Control 35(11): 1868-1879.

Levin, S., T. Xepapadeas, A-S. Crépin, J. Norberg, A. de Zeeuw, C. Folke, T. Hughes et al. 2013. 'Social-Ecological Systems as Complex Adaptive Systems: Modeling and Policy Implications.' Environment and Development Economics 18(2): 111-132.

Mäler, K.G., A. Xepapadeas, and A. de Zeeuw. 2003. 'The Economics of Shallow Lakes.' Environmental and Resource Economics 26(4): 603-624.

Mendoza, G.A., and H. Martins. 2006. 'Multi-criteria Decision Analysis in Natural Resource Management: A Critical Review of Methods and New Modelling Paradigms.' Forest Ecology and Management 230(1): 1-22.

Morgan, M.G., and M. Henrion. 1990. Uncertainty: A Guide to Dealing with Uncertainty in Quantitative Risk and Policy Analysis. Cambridge: Cambridge University Press.

Myerson, R.B. 2013. Game Theory. Cambridge: Harvard University Press.

Pearce, D., G. Atkinson, and S. Mourato. 2006. Cost-benefit Analysis and the Environment: Recent Developments. Paris: OECD.

Peterson, G.D., S.R. Carpenter, and W.A. Brock. 2003. 'Uncertainty and the Management of Multistate Ecosystems: An Apparently Rational Route to Collapse.' Ecology 84(6): 1403-1411.

Polasky, S., and S. Binder. 2012. 'Valuing the Environment for Decision-making.' Issues in Science and Technology 28(4): 53-62.

Polasky, S., S.R. Carpenter, C. Folke, and B. Keeler. 2011. 'Decision-making under Great Uncertainty: Environmental Management in an Era of Global Change.' Trends in Ecology and Evolution 26(8): 398-404.

Polasky, S., A. de Zeeuw, and F. Wagener. 2011. 'Optimal Management with Potential Regime Shifts.' Journal of Environmental Economics and Management 62(2): 229-240.

Polasky, S., D. Lewis, A. Plantinga, and E. Nelson. 2014. 'Implementing the Optimal Provision of Ecosystem Services.' Proceedings of the National Academy of Sciences 111(17): 6248-6253.

Polasky, S., E. Nelson, J. Camm, B. Csuti, P. Fackler, E. Lonsdorf, C. Montgomery et al. 2008. 'Where to Put Things? Spatial Land Management to Sustain Biodiversity and Economic Returns.' Biological Conservation 141(6): 1505-1524.

Quaas, M.F., T. Requate, K. Ruckes, A. Skonhoft, N. Vestergaard, and R. Voss. 2013. 'Incentives for Optimal Management of Age-structured Fish Populations.' Resource and Energy Economics 35(2): $113-134$.

Robinson, E.J., J.C. Williams, and H.J. Albers. 2002. 'The Influence of Markets and Policy on Spatial Patterns of Non-Timber Forest Product Extraction.' Land Economics 78(2): 260-271.

Schill, C., T. Lindahl, and A-S. Crépin. 2015. 'Collective Action and the Risk of Ecosystem Regime Shifts: Insights from a Laboratory Experiment.' Ecology and Society 20(1): 48.

Shogren, J.F., and L.O. Taylor. 2008. 'On Behavioral-environmental Economics.' Review of Environmental Economics and Policy 2(1): 26-44.

Skiba, A.K. 1978. 'Optimal Growth with a Convex-concave Production Function.' Econometrica 46(3): $527-539$.

Smith, M.D., J.N. Sanchirico, and J.E. Wilen. 2009. 'Economics of Spatial-dynamic Processes: Applications to Renewable Resource Use.' Journal of Environmental Economics and Management 57(1): 104-121.

Tavoni, A., M. Schlüter, and S. Levin. 2012. 'The Survival of the Conformist: Social Pressure and Renewable Resource Management.' Journal of Theoretical Biology 299: 152-161.

Van der Heide, C.M., J.C. van den Bergh, and E.C. van Ierland. 2005. 'Extending Weitzman's Economic Ranking of Biodiversity Protection: Combining Ecological and Genetic Considerations.' Ecological Economics 55(2): 218-223.

Watson, J.E., H.S. Grantham, K.A. Wilson, and H.P. Possingham. 2011. 'Systematic Conservation Planning: Past, Present and Future.' In Conservation Biogeography, edited by R.J. Ladle and R.J. Whittaker, 136-160. Hoboken: John Wiley \& Sons.

Wegner, G., and U. Pascual. 2011. 'Cost-benefit Analysis in the Context of Ecosystem Services for Human Well-being: A Multidisciplinary Critique.' Global Environmental Change 21(2): 492-504. 